\title{
REPORT OF THE WORKSHOP, "LIQUID SCINTILLATION COUNTING” 18-19 MAY 1991
}

New and old faces were present at the Liquid Scintillation (LS) Workshop organized and chaired by Robert Kalin. The venue was the incredibly beautiful Westward Look Resort in the foothills of Tucson, Arizona. The house was full, and the two-day Workshop lively, instructive and clearly indicative of the merit LS spectrometry serves as a major radiocarbon dating tool.

Why was LS spectrometry singled out as a Workshop topic when techniques such as gas proportional counting and accelerator mass spectrometry have an equal claim for achievement and excellence in ${ }^{14} \mathrm{C}$ dating? The answer is far more complex than given below, but one of the factors certainly is that electronic instrumentation manufacturers in Finland, Japan and the USA have made sophisticated LS counters available at reasonable cost and of such low-level counting capability that $95 \%$ of newly established ${ }^{14} \mathrm{C}$.laboratories choose LS spectrometry; currently, more than $50 \%$ of all registered ${ }^{14} \mathrm{C}$ laboratories practice LS counting.

Liquid scintillation counting has become a very specialized field, served by its own international conferences, during which aspects of low-level counting (hence, also ${ }^{14} \mathrm{C}$ dating) are invariably discussed in depth, e.g., "Liquid Scintillation Counting and Organic Scintillators" (Ross, Noakes and Spaulding 1991). Scientists whose names have become synonymous with LS spectrometry, notably, John Noakes and Jerry Stipp, shared in discussions that marked advances of LS technology, which they pioneered only 27 years ago. Certainly, in response to a push-pull effect between providers and consumers of ${ }^{14} \mathrm{C}$ dates, the technique has improved immensely, and applications have widened to encompass many specialized fields. Currently, data quality and precision are of paramount importance, as evidenced, for example, in "Radiocarbon After Four Decades: An Interdisciplinary Perspective" (Taylor, Long and Kra 1992).

Topics covered included laboratory record-keeping, relations of sample and event, and interpretation of results, topics fundamental to all ${ }^{14} \mathrm{C}$ daters. LS topics discussed in detail were benzene synthesis procedures, the merit of available catalysts, counting vial and scintillator selection, counting techniques on old counters and modern LS spectrometers, ranging from fixed-window to software-controlled windowless spectrometry, counting statistics, age calculations and quality assurance/control.

Many attendees also had the opportunity to meet again at the International Conference on Advances in Liquid Scintillation Spectrometry, Vienna, Austria, 14-18 September 1992. The Austrian Society for Liquid Scintillation Spectrometry sponsored this meeting, whose chief organizer was Franz Schönhofer; RADIOCARBON is now publishing the Proceedings. The next LS conference will precede the 15th International Radiocarbon Conference in Glasgow, August 1994. Gordon Cook will organize the conference, after which a Proceedings will be published.

A tradition of communication, both in discussions and publications, is tantamount to understanding the principles underpinning modern LS spectrometry. It is my hope that this tradition will continue to guarantee the success of technological advances in LS spectrometry and ${ }^{14} \mathrm{C}$ dating.

Henry A. Polach

Research Consultations, GPO Box 43, Garran ACT, Australia 2605 